\title{
9 \\ Influence of Air Pocket Volume on Manhole Surge
}

\section{Steven J. Wright}

Large discrete air pockets trapped along the crown of a nearly horizontal stormwater tunnel have been shown in laboratory experiments to produce large vertical surges of water as the air is expelled through a vertical riser connected to the tunnel crown. The phenomenon has been hypothesized as the source of observed geysers from manholes in such systems. A previous theoretical framework that assumes an unlimited supply of air has been shown to reproduce the essential details of laboratory experiments although deviations were observed in tests with smaller air volumes. However, it is clear that if the air volume is sufficiently small, reduced surges must occur. Previous experiments also indicate that riser diameter is a significant parameter with smaller diameters resulting in larger surges.

Experiments were conducted in which the air pocket volume and riser diameter were systematically varied. Vertical surges (when normalized by the tunnel diameter) from $\sim 0.2$ to $>25$ were observed, confirming that larger surges were associated with larger air pocket volumes and smaller riser diameters. Both variables have significant influence on the observed surge. The experiments suggest that a minimum air pocket volume when normalized by the cube of the tunnel diameter is necessary in order to attain the maximum surge levels.

In addition, the experiments recorded transient pressures near the base of the riser. These pressure traces showed significant similarity to pressures recorded during geyser events in a large stormwater tunnel, which gives support to previous arguments that geysers observed from manholes in stormwater tunnels are associated with the release of discrete pockets of trapped air.

Wright, S.J. 2013. "Influence of Air Pocket Volume on Manhole Surge." Journal of Water Management Modeling R246-09. doi: 10.14796/JWMM.R246-09.

(C) CHI 2013 www.chijournal.org ISSN: 2292-6062 (Formerly in Pragmatic Modeling of Urban Water Systems. ISBN: 978-0-9808853-8-5) 


\subsection{Introduction}

A phenomenon referred to as geysering has been reported in the literature, and captured by a number of amateur video recordings at manholes in sewer systems and other hydraulic systems that involve a vertical riser attached to a nearly horizontal conduit. Geysers are manifest as eruptions of what appears to be an air-water mixture from the vertical risers during rapid filling events in the horizontal conduit. Geysering was originally attributed in the literature to inertial surge in the water phase (e.g. Guo and Song, 1991). However, Wright et al. (2007), Lewis and Wright (2012) and others have argued that the formation of geysers in stormwater systems involves a complex interaction between air and water. Vasconcelos and Wright (2006) have suggested a number of mechanisms by which a rapidly filling pipeline could create trapped air pockets. Vasconcelos and Wright (2011) and Lewis (2011) have presented the results of small scale laboratory experiments that suggest that geysers occur as an entrapped pocket of air, migrating along the crown of a nearly horizontal surcharged tunnel, reaches a vertical riser; the rising air forces the water up ahead of it as it is expelled. The laboratory experiments do not reproduce all the phenomena observed in large scale systems and the differences are attributed to scale effects in the small scale experiments. Wright et al. (2011) present the results of video and pressure measurements at a riser in a stormwater tunnel in Minneapolis, Minnesota to argue that the observations are consistent with the release of discrete air pockets and not surge in the liquid phase.

Vasconcelos and Wright (2011) presented a numerical modeling framework that could reproduce the essential features of both the free surface rise of the surcharged water in the vertical riser and the rise of the air bubble displacing the water. The study indicated the important influence of the riser diameter relative to the tunnel diameter, with larger vertical water displacement associated with smaller riser diameters. Lewis (2011) modified this analysis to describe an altered experimental configuration that was considered to be more representative of conditions in actual tunnel systems, and found qualitative agreement between experimental measurements and numerical predictions. It was also noted that two measures for maximum water rise could be defined: the surge level $Z_{S}$ at which the air bubble broke through the rising water interface, and splash $Z_{M}$, the maximum level that water was ejected above the surge level due to the explosive nature of the air release. The numerical schemes were implemented under the assumption of an infinite amount of air being present to supply the rising bubble in the vertical riser. Intuitively, this model cannot be applied to the case of small air pockets where it is logical that the limited amount of air will reduce the water rise in the riser. Lewis 
and Wright (2012) hypothesized that if the air pocket volume was comparable to the initial water volume in the surcharged riser or less, both $Z_{S}$ and $Z_{M}$ should be reduced. They further suggested that if the riser diameter was sufficiently large compared to the tunnel diameter, the rate at which air could be supplied to the riser should limit the magnitude of the water rise; and that the theory as proposed may not be valid since it is based on an assumption of unlimited air availability at the base of the riser. These suggestions could not be readily tested with the available experimental data since the original experiments were not designed to test these hypotheses. However, these are important issues that may have significant impact on the design of ventilation in sewer systems.

The purpose of this chapter is to present the results of additional experiments that were performed using a modification of the apparatus developed by Lewis (2011). These experiments involved a systematic variation of both the riser diameter and the volume of the released air pocket with emphasis on smaller values of each than had been generally investigated in the previous studies. The purpose was to test the two hypotheses mentioned above. Interpretation of the results provides additional insight as to approaches to mitigate geysering in sewer systems.

\subsection{Limiting Riser Diameter}

It is possible to combine two simple theoretical models to estimate a maximum $D_{R} / D_{T}$ ratio above which air cannot be supplied by the horizontal air intrusion faster than the rising air bubble will accept it, where $D_{R}$ is the diameter of the vertical riser and $D_{T}$ is the diameter of the nearly horizontal tunnel. The assumptions required for the analyses to be applied are not strictly valid in the experiments described, but it is presumed that a general estimate of the limiting ratio given by this approach is still valid.

Benjamin (1968) developed a theory for the intrusion of air into a horizontal water filled conduit which was suddenly opened at one end. The air intrudes into the water as a front, often referred to as a gravity current, with a constant speed $C$ and thickness $h$. The resulting expressions for air propagation velocity have been verified by a variety of experiments and have also been shown to be valid relative to any water flow ahead of the air intrusion (e.g. Vasconcelos and Wright, 2008). There is some question about exactly how to apply the analysis since the air intrusion appears as a loss-free front followed by a jump-like transition to a smaller depth. The analysis for a loss-free current yields a non-dimensional intrusion velocity given by $C^{*}=C /\left(g D_{T}\right)^{1 / 2}$ $=0.567$ and $h / D_{T}=0.437$, where $g$ is gravitational acceleration. Little et al. 
(2008) used a computational fluid dynamics model to estimate the change in gravity current propagation speed due to a finite air volume, and concluded that so long as $V_{a i r} /\left[(\pi / 4) D_{T}^{3}\right]>\sim 0.3$, the propagation speed is basically independent of the air volume.

The rising velocity $C_{v}$ of an air bubble inside a vertical tube closed at the top has been estimated by Davies and Taylor (1950) as $0.328\left(g D_{R}\right)^{1 / 2}$. This air bubble occupies all but the small perimeter of the tube that is occupied by down-flowing water around the bubble. Equating the two air fluxes yields the diameter ratio $D_{R} / D_{T}=0.74$. For larger riser diameters, it would be expected that the air supply from the horizontal gravity current should be less than the rising air bubble can accept, resulting in a weaker vertical surge. The geyser in Minneapolis, Minnesota reported by Wright et al. (2011) involved a system with a ratio of 0.67 , below this limit, although the tunnel shape was not circular. Significant geysering was experienced in this system. This approximate analysis can be taken to indicate that the riser diameter may need to be of the same order as the tunnel diameter in order to ensure that geysering effects are minimal with large trapped air pockets.

\subsection{Experimental Investigation}

\subsubsection{Apparatus}

The experimental apparatus is essentially the same as implemented by Lewis (2011) and described in Lewis and Wright (2012); a sketch is presented in Figure 9.1.

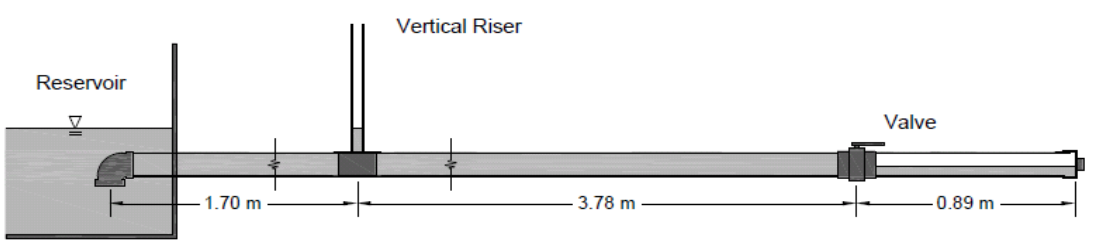

Figure 9.1 Schematic of experimental apparatus.

The reservoir head could be varied and provided the initial surcharge level in the riser. The entire $9.4 \mathrm{~cm}$ diameter horizontal conduit was initially filled with water and the control valve was closed. Air was admitted into the small volume on the right side of the valve indicated in Figure 9.1 and the water being displaced was captured and weighed. This provided the measure of the air volume. 
Once the desired air volume was added, the drain line was closed and the pipe section with air was pressurized to the same level as the reservoir, which avoided pressure oscillations in the system when the valve was opened. A piezoelectric pressure transducer was mounted on the base of the riser and recorded the pressure at $100 \mathrm{~Hz}$. The flow was initiated by suddenly opening the valve, at which point the trapped air began propagating as a gravity current towards the riser. As the air pocket reached the riser, it began to rise up, forcing water up ahead of it but with some down-flow around the perimeter.

The depletion of the water volume in the shaft resulted in the air breaking through the water interface with a subsequent splash upwards in some experiments. In the cases with small surge, there was no splash. Video cameras recorded both the air intrusion approaching the riser, from which an estimate of the intrusion velocity could be obtained, and the subsequent air bubble in the riser, from which the water surge and splash could be estimated. Note that the process of the air bubble breaking through the water interface was an extremely dynamic event, especially with small riser diameters, and it was difficult to estimate the exact moment at which that occurred.

\subsubsection{Experimental Conditions}

There were basically three control variables in the experiments: the air volume, presented in normalized form as $V^{*}=V_{\text {air }} / D_{T}^{3}$; the riser diameter, presented as the ratio $D_{R} / D_{T}$; and the reservoir head $H_{R}$, measured from the tunnel invert and presented as $H_{R} / D_{T}$. Most of the experiments were performed at a single reservoir head but one set was conducted at a head of about half the initial value in order to vary the surcharge water volume in the riser. Table 9.1 presents the range of experimental variables. The case of $H_{R} / D_{T}=4.86$ duplicates experimental conditions performed by Lewis (2011).

Table 9.1 Experimental variable ranges in experiments.

\begin{tabular}{lc}
\hline \multicolumn{1}{c}{ Range of Values } & Variable \\
\hline $1-8 ; 5-7$ conditions for each set of experiments & $V^{*}$ \\
$0.47,0.54,0.81,1.0$ & $D_{R} / D_{T}$ \\
4.86 and limited tests for 2.63 & $H_{R} / D_{T}$ \\
\hline
\end{tabular}

\subsubsection{General Observations}

Measurements of pressure at the base of the riser showed a continuous pressure decrease following the opening of the valve. Figure 9.2 presents a typical pressure trace and compares with pressures measured during a geysering 
event in the Minneapolis, Minnesota stormwater system as reported previously by Wright, et al. (2011).
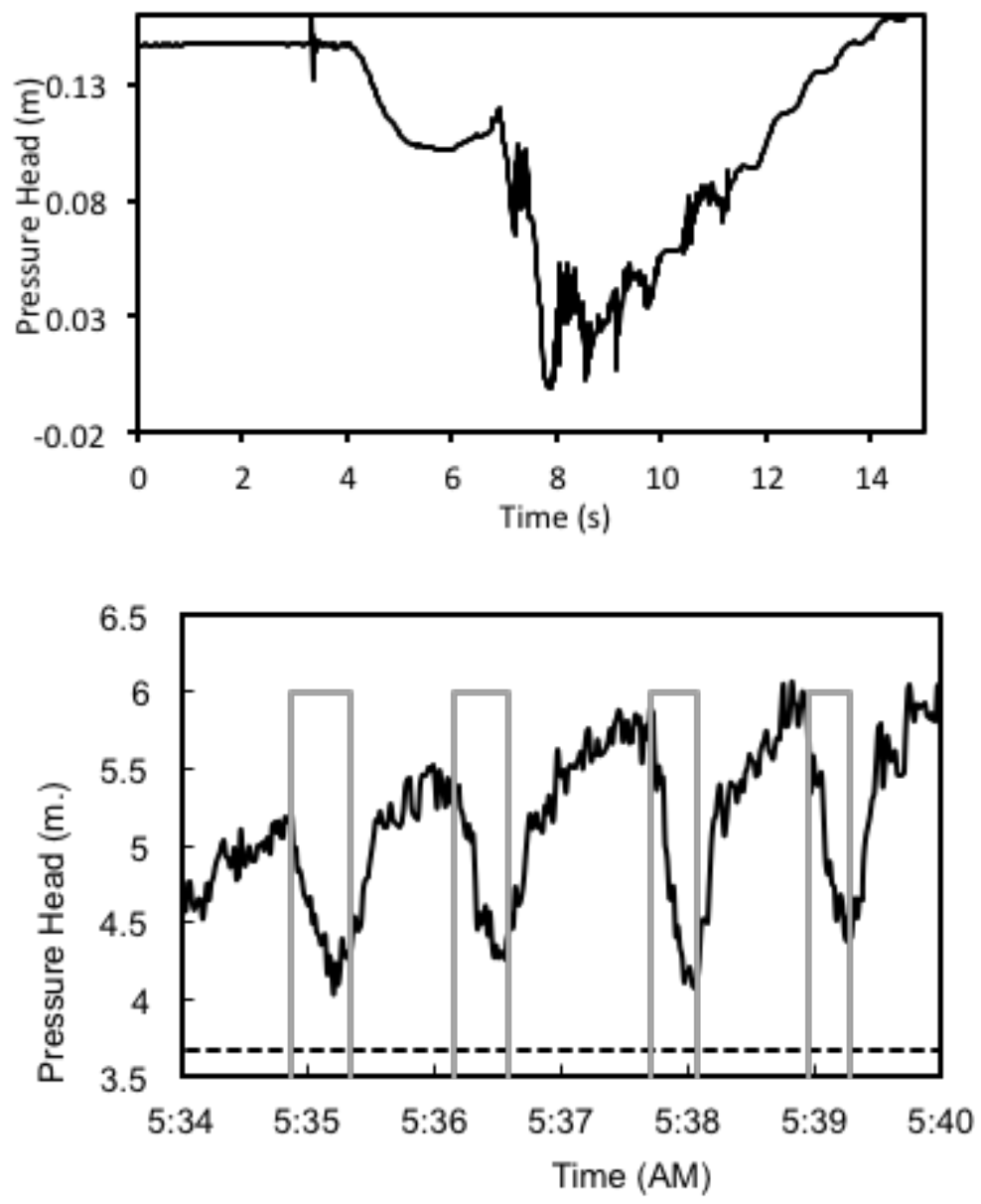

--- Tunnel Crown

Pressure

Geyser

Figure 9.2 Comparison of pressures recorded in laboratory experiments (upper) and in field measurements of geysering (lower).

There is a small fluctuation seen as a vertical line at the instant the valve is opened due to the valve operation, and noted on the figure. This is followed by a drop in pressure, predicted by the theory of Benjamin (1968), as the air intrusion begins to propagate. A sudden drop in pressure occurs as the air starts to rise in the riser at a little before seven seconds. As the air starts 
to ascend in the riser, the pressure continues to drop rapidly down to atmospheric pressure as the air bubble breaks through the interface at around eight seconds, and then slowly begins to increase as water refills the riser. The similarity between this behavior and that observed in the Minneapolis geyser is striking, although in the field data the pressure response due to the geyser is superimposed on a slowly varying transient due to the runoff event that precipitated it, and several successive events were observed. Note that the large increases in pressure that would be required in order for single phase flow inertial surge to lift water large distances in the riser do not occur in either case.

The air pocket propagated in a manner similar to what has been previously observed in gravity current experiments associated with air intrusion. The front is a distinct rounded nose followed by a smooth interface with nearly constant air thickness. Beyond the nose region, there is a jump-like transition to a smaller air thickness. Figure 9.3 depicts an experiment with a large $V^{*}$ value.

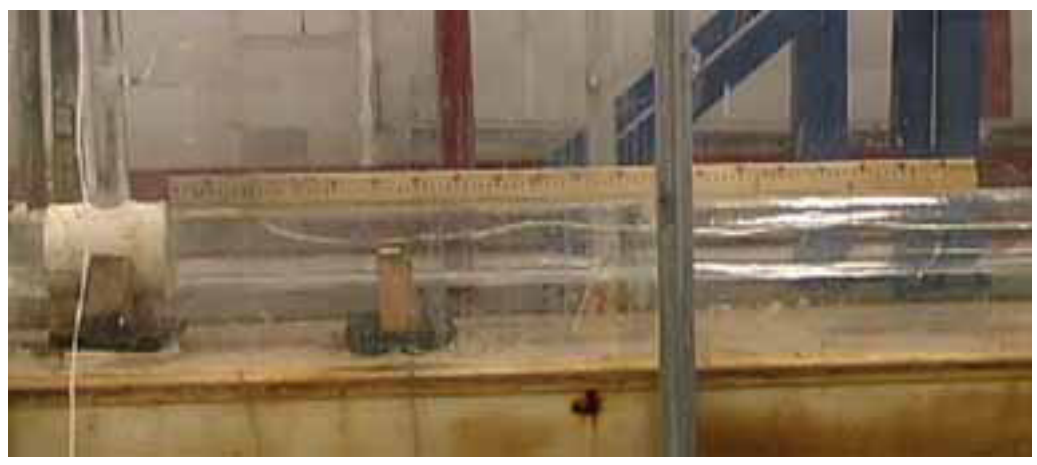

Figure 9.3 Image of air volume propagating towards riser $\left(V^{*}=6.1\right)$.

For small values of $V^{*}$, there was not the well defined trailing flow seen in Figure 9.3. The air tended to remain compact with a well defined head and a small trail of bubbles following it. The implication is that the air does not spread out into a very thin layer, but that the frontal condition imposes a state where a relatively large volume of air arrives at the riser all at once. Not all of the air in the pocket exits through the riser as a single mass, but a large quantity of it does so.

The time history of two intrusions are quite similar as they approach the riser, as indicated in Figure 9.4. The values of $V^{*}$ for the two experiments are 3.1 and 6.1, which, as discussed further below, span the transition to a limiting air volume. The data indicates a quite constant propagation velocity with $C /\left(g D_{T}\right)^{1 / 2}=\sim 0.5$, or a little less than what is suggested by the Benjamin 
(1968) theory, and in the range reported by Lewis (2011). Thus the effect of a finite air volume on the propagation speed of the intrusion is seen to be relatively minor, although the very smallest air volumes did exhibit a reduction in propagation speed. Also, the thickness of the intrusion was reduced for smaller values of $V^{*}$, such that the air flux was reduced.

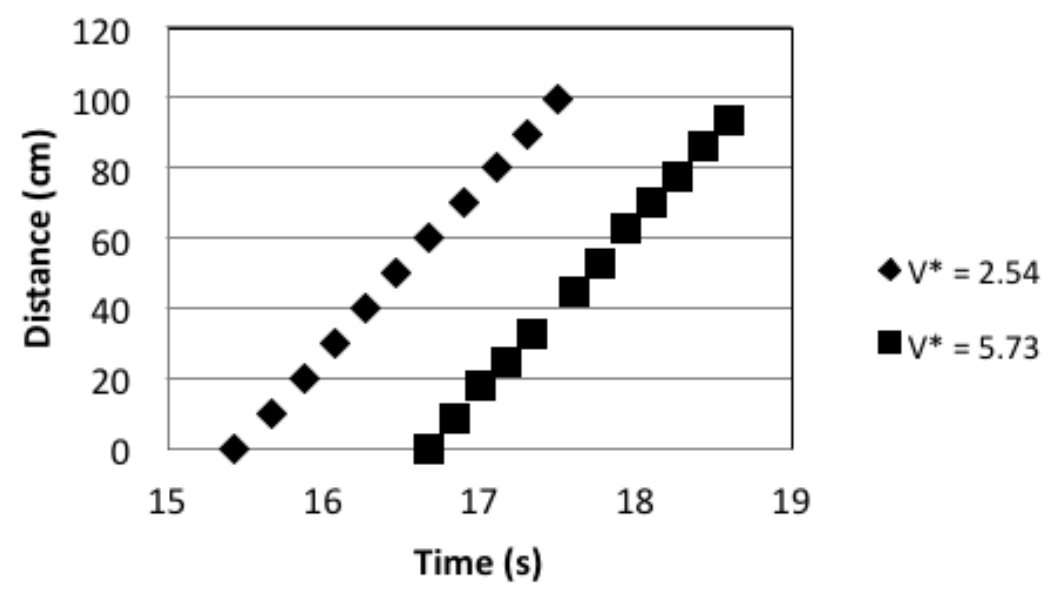

Figure 9.4 Time-displacement history of air intrusions.

\subsubsection{Surge Results}

As previously noted by Lewis (2011), the rapid vertical acceleration of the air as it rose in the riser could lift water considerable distances above the level where the air bubble broke through the rising water interface. This process was observed as a thin jet of water that, in extreme cases, could rise to a height $Z_{M}$ of approximately twice the distance $Z_{s}$ where the air bubble broke through the rising water interface. It is noted that in this extreme case, the vertical rise was so rapid that it was difficult to measure with precision exactly when the air penetrated the water interface and some interpretation of the visual images was required.

Following Lewis (2011), the results are reported for both surge and splash; in the presentation herein, these distances are reported relatively to the initial steady state level in the riser. Figure 9.5 presents the results obtained at the larger $H_{R} / D_{T}$ for the smallest $\left(D_{R} / D_{T}=0.47\right)$ riser diameter and at several different air volumes. It is seen that at small air volumes, the surge and splash heights are effectively the same. Although Lewis and Wright (2012) speculated that the key variable expressing the effect of finite air volume might be the air volume normalized by the volume of surcharged water in the riser, the 
results of the current study clearly indicated that the tunnel diameter was the more relevant variable; this is more clearly indicated in additional results presented further below, especially in Figure 9.9.

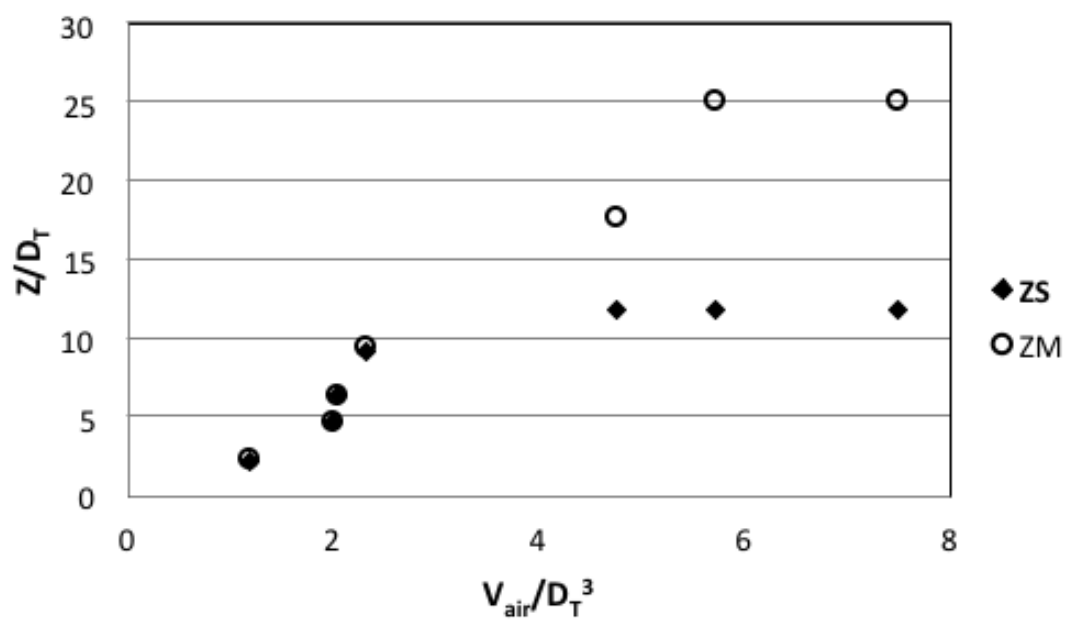

Figure 9.5 Surge and splash heights measured for various air volumes.

Figure 9.5 provides an indication that if $V^{*}>\sim 4$, the magnitude of the surge height is approximately a constant. Once the volume starts to decrease below a limiting value of $\sim 4$, then the surge height is increasingly reduced with decreasing air volume. With regards to the splash height, it appears to begin to reduce for a slightly larger value of $V^{*}$, although it is not clear that it attains a constant value at large air volumes. However, once the dimensionless volume is reduced below a value of $\sim 5$, the reduction in splash height is much more dramatic, and at the smallest air volumes, there is essentially no difference between the surge and the splash heights.

Results for other combinations of riser diameter and reservoir head as presented below indicate that these limits tend to vary somewhat but are generally consistent. Consider the implications for a large scale storage tunnel system. If a tunnel diameter of $7 \mathrm{~m}$ is considered, for example, and the data in Figure 9.5 can be extrapolated, the splash could be $>100 \mathrm{~m}$ above the initial surcharge level for a large air volume. However, for small air volumes, this is reduced down to a more acceptable $15 \mathrm{~m}$, indicating that the size of the entrapped air pocket is a critical variable in determining geyser height.

Riser diameter was also determined to be an extremely significant variable in controlling the height of the surge and splash, consistent with the general findings of Lewis (2011), although that work only investigated the 
smallest and largest riser diameters considered in this investigation. For example, Figure 9.6 presents the observations for two different values of $D_{R} / D_{T}$ (0.54 and 1.0).

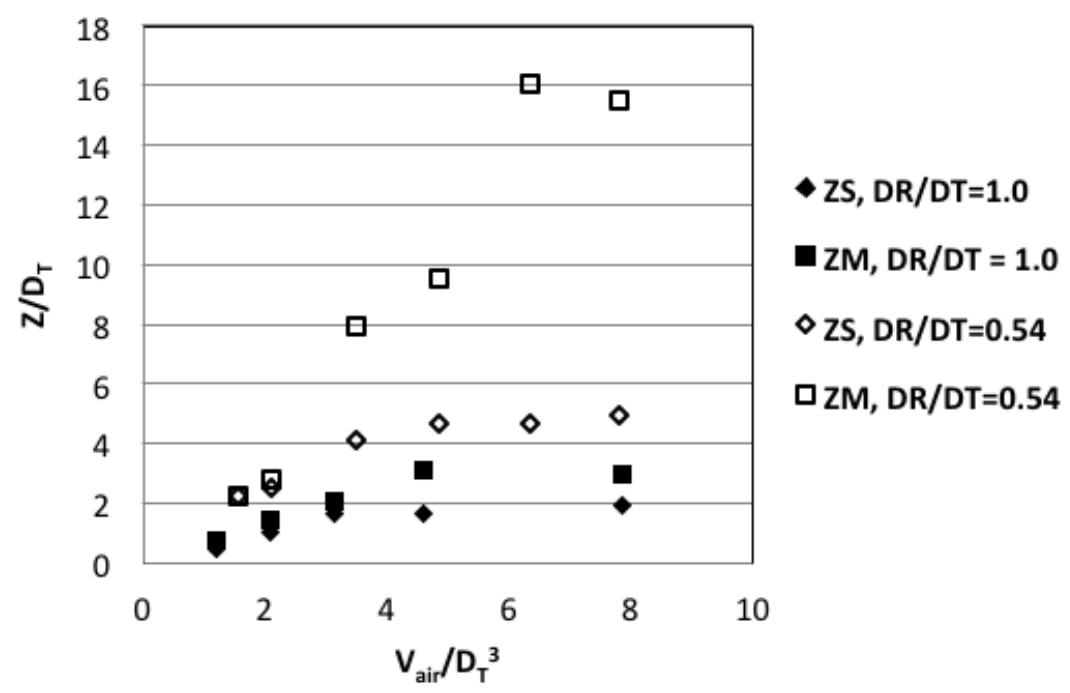

Figure 9.6 Surge and splash heights measured for two different riser diameters.

Although the trends with air volume are the same in both sets of data, note that the maximum splash height increases by a factor of $\sim 25$ as the riser diameter is reduced by a factor of $\sim 2$. If the air bubble were to rise with a velocity equal to the Davies and Taylor (1950) relation, the smaller diameter riser should have a smaller rise velocity and thus a lower increase in splash height relative to surge height, contrary to the observations. Consistent with previous observations, the smaller riser diameter creates a significant acceleration of the rising air bubble, much larger than the Davies and Taylor velocity, and thus a greater tendency to create geyser conditions. Over the entire set of experiments, the variation in splash height, considering both the effects of air volume and riser diameter is over a range of 125 from maximum to minimum observed values.

Changing the reservoir head and thus the initial surcharge level in the riser, also had an important effect on the water rise heights, as observed in Figure 9.7. Higher initial surcharge levels resulted in higher water rise, which is to be expected since the larger initial water volume in the riser take longer to drain down around the rising air bubble giving the bubble more time to rise in the vertical before the surface breakthrough occurs and the air bubble to 
generally accelerate to a higher final velocity. If the maximum splash height for all air volumes for a constant reservoir head is plotted against riser diameter ratio as indicated in Figure 9.8, there is a clear trend of rapidly increasing splash as the riser diameter decreases.

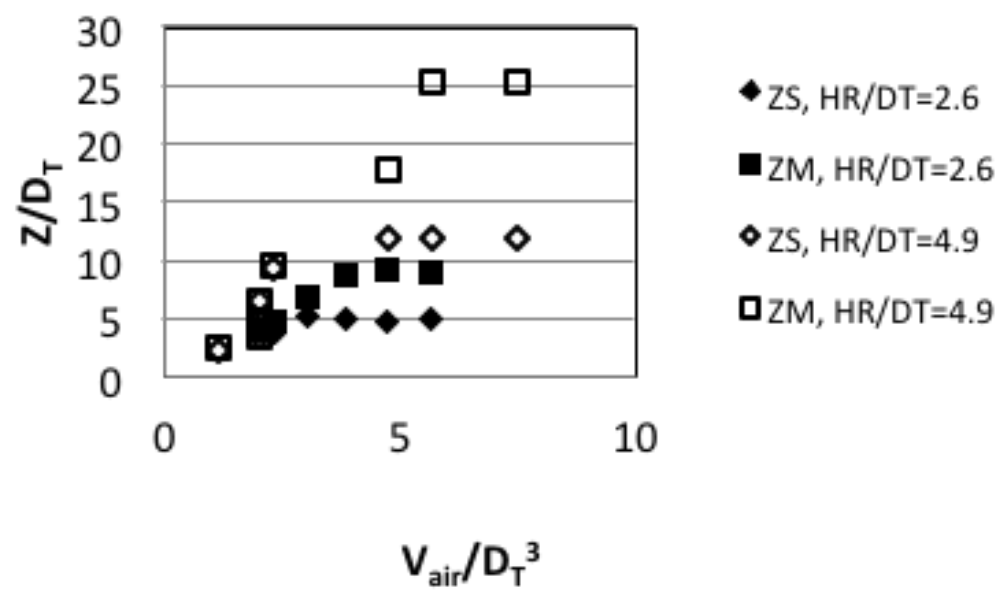

Figure 9.7 Surge and splash heights measured for different reservoir heads.

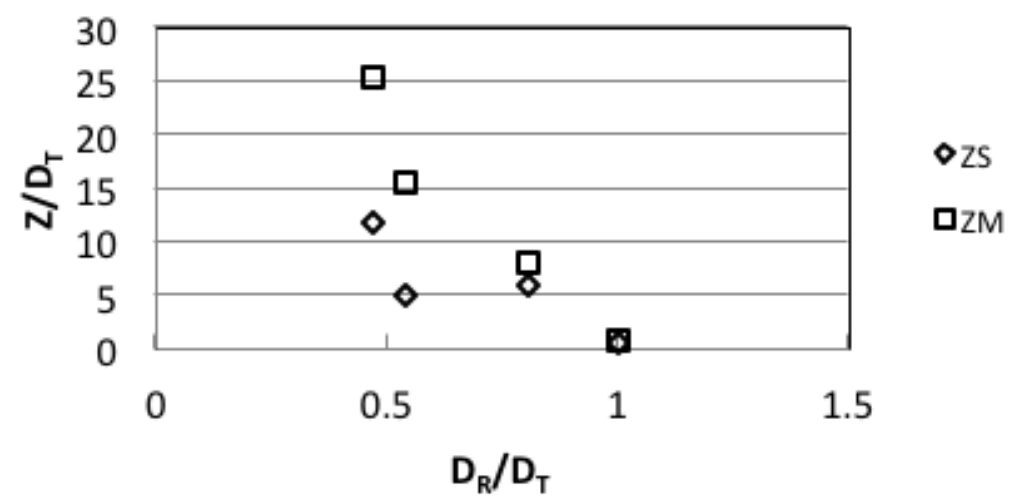

Figure 9.8 Maximum splash height as function of diameter ratio.

The approximate analysis in Section 9.2 suggested that there might be a transition in observed behavior at a $D_{R} / D_{T}$ ratio of $\sim 0.74$ and the experiments were conducted with two riser diameters above this limit and two below. There is no obvious break point in the observed behavior over the range of experiments conducted and with the observation of much higher rise velocities 
than the Davies and Taylor (1950) theory for small riser diameters, this should not be surprising. However, the data do suggest that if the riser diameter is approximately equal to the tunnel diameter, the tendency for geysering is significantly diminished. This finding may have significant implication for design of vertical risers on systems that may be susceptible to geyser formation and is supported by observations in the Minneapolis, Minnesota system in which a $D_{R} / D_{T}$ ratio of 0.67 resulted in significant geysers.

\subsubsection{Limiting Air Volume}

All test results for surge height (since it was easier to measure more accurately) as a function of dimensionless air volume are presented in Figure 9.9. It can be seen that all experimental results support a conclusion that the surge height begins to decrease from approximately a constant value when the size of the air pocket, denoted by $V^{*}$, decreases below a value of $\sim 4$. A small variation of this value is suggested by the data with this limiting value becoming smaller with initial surcharge level, although more experimentation would be required to confirm this conclusion. Consistency over the range of experimental variables indicates the speculation by Lewis and Wright (2012) that the air volume normalized by the surcharge volume in the riser might be the key variable is not correct. A remaining exercise would be to understand what size of typical air pocket volumes might be expected in scenarios associated with rapid filling in prototype systems in order to understand the potential effect on geysering.

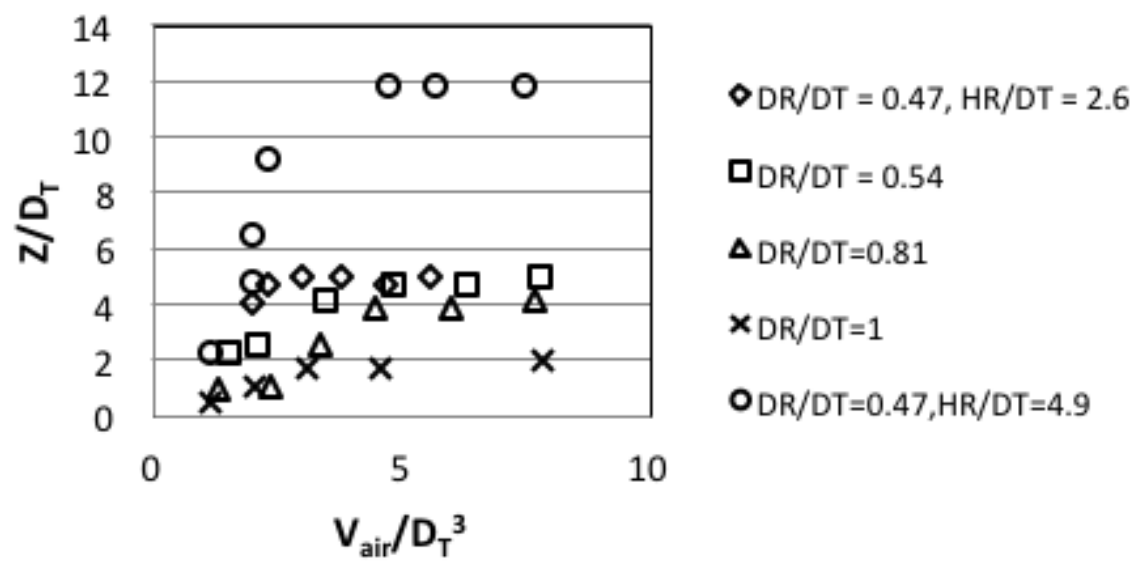

Figure 9.9 Surge heights as function of air volume measured for all riser diameters and reservoir heads. 


\subsection{Conclusions}

Although experiments of the type presented in this chapter have been conducted in the past by Lewis (2011) and Vasconcelos and Wright (2011), they have primarily concentrated on the behavior of relatively large air pocket volumes. Also the experiments by Vasconcelos and Wright were all performed with a riser height of $0.61 \mathrm{~m}$ and could only observe that for large vertical surges the water spilled out the top of the riser. The experiments described in this study systematically varied the air volume and riser diameter (with a riser height sufficiently large to contain the splash within it) in order to determine the scaling relationships of air volume to system geometry and the air volume above which the water rise in a vertical riser is not limited by the air volume. The experimental results provide preliminary answers to these questions. In addition, the results have implications with regards to current modeling efforts to predict the geyser effect. The following conclusions are supported by the findings of this study:

1. A measurement of transient pressures during the propagation of a discrete air pocket along the crown of the horizontal pipe and up through the vertical riser shows similarity to pressure measurements made in a field setting. In particular, the ejection of water above grade involves a drop in local pressure at the base of the riser as the air propagates upwards and it is not necessary for the hydraulic grade line to come close to the ground surface in order to create a geyser condition;

2. The ratio of the riser diameter to the tunnel diameter is a key variable in determining the strength of the geyser response. The larger the ratio, the smaller the response. Based on the results of this and previous studies, it is recommended that the riser diameter be at least equal to the tunnel diameter to avoid a strong geyser. This recommendation is subject to the qualification that the small scale laboratory experiments in this study will not correctly reproduce all dynamic effects;

3. The experiments show that water can be ejected over significant vertical distances above the level where the air pocket breaks through the rising water interface in the riser. The effect is much more pronounced at small riser diameter ratios, indicating a stronger tendency for the ejection of an air water mixture at smaller relative riser diameters;

4. Observations suggest that when the dimensionless air volume $V^{*}=V_{\text {air }} / D_{T}^{3}<\sim 4$, the finite size of the air pocket will have an 
effect in reducing the strength of the geyser. It remains to be demonstrated how significant this effect is in actual applications;

5. When the dimensionless air volume is below the above mentioned limit (and also potentially for large relative riser diameters), numerical modeling approaches such as developed by Vasconcelos and Wright (2011) and Lewis (2011) cannot be applied since they assume an unlimited supply of air at the base of the riser. Further investigation will be required in order to establish whether modifications to those model approaches can be developed to account for the limited air supply; and

6. In any case, the numerical modeling approaches described above can only be applied to the level at which the air pocket breaks through the rising water interface. The subsequent splash above that level cannot be captured by the numerical framework. It is also unclear whether the small scale laboratory observations can be dynamically scaled to prototype applications.

\section{Acknowledgment}

Greg Ewing assisted in conducting the experiments described in this chapter.

\section{References}

Benjamin, T. B. (1968). Gravity currents and related phenomena. Journal of Fluid Mechanics 31(2), pp 209-248.

Davies, R. M. and Taylor, G. I. (1950). The mechanics of large bubbles rising through extended liquids and through liquids in tubes. Proceedings of the Royal Society of London Series A, Mathematical and Physical Sciences, Vol. 200(1062), pp 375-390.

Guo, Q. and Song, C. C. S. (1991). Dropriser hydrodynamics under transient conditions. Journal of Hydraulic Engineering 117(8), pp 1042-1055.

Lewis, J. W. (2011). A Physical Investigation of Air-Water Interactions Leading to Geyser Events in Rapid Filling Pipelines. PhD dissertation presented to Civil and Environmental Engineering Department, University of Michigan, Ann Arbor, MI

Lewis, J., S.J. Wright and J. Vasconcelos. 2011. "Mechanisms for Surges in Vertical Shafts in Stormwater Tunnels." Journal of Water Management Modeling R241-03. doi: 10.14796/JWMM.R241-03.

Lewis, J. and S.J. Wright. 2012. "Air-Water Interactions that Generate Large Water Lift through Vertical Shafts in Stormwater Conduits." Journal of Water Management Modeling R245-02. doi: 10.14796/JWMM.R245-02. 
Little, M. J., Powell, J. C. and Clark, P. B. (2008). Air Movement in Pipelines - some new developments. 10th International Conference on Pressure Surges. Edinburgh: BHR Group Ltd. pp 111-122.

Vasconcelos J. G. and Wright, S. J. (2006). Mechanisms for Air Pocket Entrapment in Stormwater Storage Tunnels. Proceedings of World Water and Environmental Resources Congress, Omaha, Nebraska, Paper 40856-14275.

Vasconcelos, J. G. and Wright, S. J. (2008). Rapid flow startup in filled horizontal pipelines. Journal of Hydraulic Engineering, 134(7), pp 984-992.

Vasconcelos, J. G. and Wright, S. J. (2011). Geysering generated by large air pockets released through water-filled ventilation risers. Journal of Hydraulic Engineering 137(5), pp 543-555.

Wright, S.J., J. Lewis and J. Vasconcelos. 2007. "Mechanisms for Stormwater Surges in Vertical Shafts." Journal of Water Management Modeling R227-05. doi: 10.14796/JWMM.R227-05.

Wright, S. J., Lewis, J. W. and Vasconcelos, J. G. (2011). Geysering in rapidly filling stormwater tunnels. Journal of Hydraulic Engineering 137(1), pp 112-115. 
